\title{
CONTAGEM AUTOMÁTICA E MICROSCÓPICA DIRETA DAS CÉLULAS SOMÁTICAS DO LEITE DE OVELHAS DA RAÇA LACAUNE, UTILIZANDO COMO CORANTES O ROSENFELD E VERDE DE METIL E PIRONINA-Y
}

\author{
Viviani Gomes, ${ }^{1}$ Ana Lígia Amato, ${ }^{2}$ Gabriela Carla T. G. Ponte, ${ }^{3}$ Maiara Blagitz, ${ }^{4}$ Karina Medici \\ Madureira $^{5}$ e Alice Maria Melville Paiva Della Libera ${ }^{6}$
}

1. Doutora pelo Departamento de Clínica Médica, Faculdade de Medicina Veterinária e Zootecnia, FMVZ/USP

2. Discente da Faculdade de Medicina Veterinária da Universidade Paulista, UNIP

3. Discente da Faculdade de Medicina Veterinária da Universidade Paulista, UNIP

4. Doutoranda pelo Departamento de Clínica Médica da Faculdade de Medicina Veterinária e Zootecnia da Universidade de São Paulo, FMVZ/USP 5. Doutoranda do Departamento de Clínica Médica da Faculdade de Medicina Veterinária e Zootecnia, FMVZ/USP. E-mail: karinamedici@yahoo.com.br 6. Docente da Faculdade de Medicina Veterinária e Zootecnia da Universidade de São Paulo, FMVZ/USP.

\section{RESUMO}

O presente estudo teve como objetivo a análise da celularidade, a comparação dos diferentes métodos de contagem celular e a quantificação dos diferentes tipos celulares presentes no leite de ovelha da raça Lacaune através da contagem de células somáticas (CCS) automática e da CCS microscópica. Coraram-se os esfregaços lácteos com os corantes verde de metil e pironina-Y e Rosenfeld. O valor mediano da contagem celular automática foi de $0,145 \times 10^{6}$ células $/ \mathrm{mL}$ de leite, e os valores das contagens microscópicas diretas utilizando verde de metil e pironina-Y e Rosenfeld foram respectivamente de 0,157 e 0,193 $\mathrm{x} 10^{6}$ células $/ \mathrm{mL}$ de leite. Avaliaram-se as amostras destinadas às contagens microscópicas diretas de acordo com os diferentes tipos celulares, encontrando-se os valores de 0,094 e $0,14 \times 10^{6}$ células mononucleares/mL, 0,063 e 0,051 x106 células polimorfonuclares/ $\mathrm{mL}$ de leite na coloração de verde de metil e pironina-Y e Rosenfeld, respectivamente. Portanto, pode-se concluir que houve diferenças entre os métodos de contagem celular. Com o corante verde de metil e pironina-Y e a contagem automática, o número de células encontrado foi inferior, quando comparados com a microscopia direta utilizando o corante de Rosenfeld.

PALAVRAS-CHAVES: Células somáticas e citologia, Lacaune, leite, ovelha.

\section{ABSTRACT}

\section{AUTOMATIC AND DIRECT MICROSCOPIC SOMATIC CELLS COUNT OF LACAUNE DAIRY SHEEP, USING THE ROSENFELD AND METHYL GREEN-PIRONIN STAINS}

The objectives of the present study were the analysis of cell counts, the comparison between different methods for counting cells and the quantification of different types of cells observed in the milk of Lacaune sheep, using automatic somatic cell counts (SCC) and direct microscopic SCC. Milk smears were stained with methyl green-pyronin-Y and Rosenfeld stain. Mean of automatic cell counts was $0.145 \times 10^{6}$ cells $/ \mathrm{mL}$ of milk, and mean of direct microscopic counts using methyl green-pyronin-Y and Rosenfeld were respectively 0.157 and $0.193 \times 10^{6}$ cells $/ \mathrm{mL}$ of milk. Samples

KEY WORDS: Somatic cells and cytology, lacaune, milk, sheep. used in direct microscopic counts were evaluated according to the different types of cells and the following results were recorded: 0.094 and $0.14 \times 10^{6}$ mononuclear cells $/ \mathrm{mL}, 0.063$ and $0.051 \times 10^{6}$ polymorphonuclear cells $/ \mathrm{mL}$ of milk using methyl green-pyronin-Y and Rosenfeld stain, respectively. It may be concluded that there were differences in the methods used for counting cells. The number of cells recorded was lower when methyl green-pyronin-Y and automatic counts were used, compared with direct microscopy using Rosenfeld stain. 


\section{INTRODUÇÃO}

A glândula mamária dos pequenos ruminantes apresenta particularidades fisiológicas durante sua secreção (PAAPE et al., 2001). A glândula mamária é considerada glândula com secreção do tipo apócrina. Durante a lactação, secreta corpúsculos resultantes do desprendimento das células do epitélio de revestimento dos alvéolos (CONTRERAS et al., 1996; PAAPE et al., 2001). Muitos desses corpúsculos não apresentam núcleos, porém alguns deles são eliminados com eles (GOMES et al., 2002). Apesar de serem muitas vezes anucleados, são semelhantes no tamanho e na morfologia aos leucócitos e, dessa forma, podem ser confundidos com as células somáticas (GOMES et al., 2006). Por esse motivo, é recomendada a utilização de métodos de contagem celular específicos para células nucleadas (DNA) (CONTRERAS et al., 1996; GOMES et al., 2006).

As contagens mais conhecidas são a contagem de células somáticas (CCS) automática e a CCS microscópica. Para a CCS automática, é necessário o envio das amostras para laboratórios especializados, além da padronização do aparelho para o leite de ovelhas, estudo ausente na literatura brasileira. Para a CCS microscópica, é necessário apenas o conhecimento de colorações mais adequadas para a secreção láctea da espécie a ser avaliada (PENGOV, 2001).

As colorações ideais para o leite dos pequenos ruminantes ainda são discutíveis. GONZALO et al. (2003) verificaram falhas na coloração de azul de metileno, que, por ser inespecífico entre as células e os corpúsculos citoplasmáticos, induziu alterações nas contagens celulares. GOMES et al. (2006) observaram que uma das colorações ideais para a CCS microscópica em ovelhas da raça Lacaune foi a pyronina-Y. BARBOSA et al. (2006), trabalhando com leite de ovelhas da raça Santa Inês, concluíram que a coloração por Broadhurt-Palley foi mais eficiente que a coloração por hematoxilina-eosina.

A contagem microscópica direta com verde de metil e pironina-Y, corante DNA-específico, é o método referendado como padrão para avaliar a contagem de células somáticas no leite de cabras, que também possui secreção láctea do tipo apócrina, pois possibilita a coloração apenas das células nucleadas e permite a exclusão dos corpúsculos citoplasmáticos do leite (ZENG et al., 1997).

A contagem eletrônica de células somáticas em equipamentos baseados em citometria de fluxo (Somacount ou Fossomatic) e a contagem microscópica direta, utilizando-se corante não específico para DNA, são utilizadas para a enumeração das células do leite de vacas, mas precisam ser analisadas para a utilização em ovelhas, pois podem elevar aparentemente a concentração de leucócitos no leite dessa espécime, principalmente porque o contador automático é calibrado com o leite de vacas.

A CCS pode ser influenciada por fatores fisiológicos, como estresse, fase da lactação, idade da fêmea (BOSCOS et al., 1996; CONTRERAS et al., 1996; LAFI et al., 1998; SEVI et al., 2000; PAAPE et al., 2001; ALBENZIO et al., 2003; BERGONIER et al., 2003; LEITNER et al., 2003; BIANCHI et al., 2004; GONZALO et al., 2004; ANDERSON et al., 2005), número de lactações, frações do leite, raças, estados nutricionais (GONZÁLEZ-RODRÍGUEZ et al., 1995; FTHENAKIS, 1996; PAAPE et al., 2001; BERGONIER et al., 2003; ANDERSON et al., 2005) e por fatores patológicos como a infecção intramamária (CONTRERAS et al., 1996; KIRK et al., 1996; BURRIEL, 2000; PAAPE et al., 2001; BERGONIER et al., 2003).

BRITO et al. (2006) avaliaram o leite de cem ovelhas da raça Lacaune em diferentes fases de lactação, criadas no Sul do Brasil, e verificaram o valor médio de $0,171 \times 10^{6}$ células $/ \mathrm{mL}$ de leite, utilizando contagem automática por citometria de fluxo. O estudo de BARBOSA et al. (2006) mostrou variações celulares decorrentes da raça Santa Inês, com valor mediano de $0,176,0,114$ e $0,205 \times 10^{6}$ células somáticas $/ \mathrm{mL}$ de leite, em que se utilizou contador automático e se realizou contagem microscópica direta com coloração de hematoxilina-eosina e Broadhurst-Paley, corantes não específicos para DNA.

Em função da escassez de pesquisas internacionais e nacionais sobre a celularidade do leite de ovelhas, bem como de técnicas empregadas para a enumeração dessas células, a presente pesquisa teve como objetivo a análise da celularidade, a comparação dos diferentes métodos de contagem celular e a quantificação dos diferentes tipos celulares presentes no leite de ovelhas da raça Lacaune. 


\section{MATERIAL E MÉTODOS}

No estudo realizado, procedeu-se à análise de duzentas amostras de leite, provenientes das metades mamárias de cem ovelhas da raça Lacaune, em diferentes fases de lactação, oriundas de um rebanho localizado no estado do Rio Grande do Sul. Excluíram-se, dessa investigação, as fêmeas ovinas que apresentaram alteração no exame físico da glândula mamária.

Antes do início da ordenha, colheram-se, das metades mamárias, amostras de leite, as quais, posteriormente, foram divididas em três alíquotas. Colheuse a primeira alíquota de leite em frasco plástico com capacidade de $40 \mathrm{~mL}$, contendo duas pastilhas do conservante Bronopol ${ }^{\circledR}$ (2-bromo-2nitropropane-1,3-diol), para a realização da contagem automática de células somáticas, realizada por citometria de fluxo utilizando-se o equipamento Somacount 300 (Bentley Instruments $^{\circledR}$ ) (BRITO et al., 2006).

Para a realização da contagem microscópica direta, foi colhida uma segunda alíquota, em frascos de vidro com capacidade de $3 \mathrm{~mL}$. Para tanto, distribuíram-se $10 \mu \mathrm{L}$ de leite em uma área de um $\mathrm{cm}^{2}$, em lâmina de microscopia. Em seguida, a lâmina foi seca em temperatura ambiente por 24 horas (PRESCOTT \& BREED, 1910). Para a coloração das lâminas, utilizaram-se dois corantes, o verde de metil e pironina-Y e o Rosenfeld, com preparo das lâminas em duplicata para cada tipo de corante. Para a realização da coloração com verde de metil e pironina-Y, fixaram-se as lâminas em solução de Carnoy's por dez minutos. Depois de fixadas, as lâminas foram hidratadas e coradas em solução fresca preparada com verde de metil e pironina-Y, segundo procedimentos descritos por ZENG et al. (1999). Para a coloração de Rosenfeld, as lâminas foram fixadas em metanol por dez minutos, e coradas segundo a técnica descrita por ROSENFELD (1947). Para a determinação do número de células, procedeu-se às contagens em duplicata, para os dois tipos de corantes utilizados. Efetuou-se a contagem das células presentes em cem campos visuais das duas lâminas confeccionadas, usando uma objetiva de imersão (100x e objetiva 10x). Para a obtenção do resultado final, obteve-se a média das duas contagens, para cada tipo de corante utilizado, e multiplicou-se a média pelo fator do microscópio previamente calculado, expressando-se o resultado em número de células somáticas por $\mathrm{mL}$ de leite (ZENG et al., 1999).

Destinou-se a terceira alíquota da amostra ao exame bacteriológico, precedida de cuidados de antissepsia, colhida em frasco estéril e transportada sob refrigeração ao laboratório (INTERNATIONAL DAIRY FEDERATION, 1981). As alíquotas de leite foram semeadas em placa Petri contendo ágar sangue de ovino a $5 \%$ e incubadas a $37^{\circ} \mathrm{C}$ durante 72 horas (KRIEG \& HOLT, 1984). Excluíram-se dessa investigação as amostras positivas ao exame bacteriológico do leite.

Para análise estatística, inicialmente os resultados foram submetidos ao teste de normalidade de Kolmogorov-Smirnov e todos apresentaram distribuição não paramétrica, tendo seus valores expressos em mediana. A contagem total de células somáticas, considerando os três métodos avaliados, foi submetida ao teste de Friedman seguido de pós-teste de comparação múltipla de Dunn (Dunn's Multiple Comparison Test). A comparação entre leucócitos mononucleares e polimorfonucleares pelas duas diferentes colorações foi comparada pelo teste de postos com sinais de Wilcoxon (Wilcoxon Signed-Rank Test). As análises estatísticas seguiram as recomendações de SAMPAIO (2002), sendo realizadas com auxílio de software estatístico (MINITAB, 2000). Neste trabalho foi considerado um nível de significância de 5\%.

\section{RESULTADOS E DISCUSSÃO}

Das duzentas amostras de leite colhidas, utilizaram-se 184 para a análise citológica do leite, pois foram excluídas as dezesseis amostras que apresentaram isolamento positivo ao exame bacteriológico.

A média da CCS, realizada em equipamento automático, foi de $0,114 \times 10^{6}$ células $/ \mathrm{mL}$ de leite, valor inferior aos encontrados mediante contagem microscópica direta, utilizando-se os métodos de coloração de verde de metil e pironina-Y e Rosenfeld. Os valores medianos observados foram de 0,157 e 0,193 x $10^{6}$ células $/ \mathrm{mL}$ de leite, respectivamente $(p<0,0001)$, registrando-se diferenças entre os métodos de contagem celular analisados (Tabela 1). 
TABELA 1. Contagem de células somáticas no leite de ovelhas Lacaune hígidas criadas no Rio Grande do Sul

\begin{tabular}{lc}
\hline \multicolumn{1}{c}{ Métodos de contagem celular } & $\begin{array}{c}\text { x } 10^{6} \text { células somáticas/ } \\
\mathrm{mL} \text { de leite }\end{array}$ \\
\hline Automática & $114.500^{\mathrm{c}}$ \\
Verde de metil e mironina-Y & $157.480^{\mathrm{b}}$ \\
Rosenfeld & $192.570^{\mathrm{a}}$ \\
Significância $(\mathrm{p})$ & $\mathrm{P}<0,00001$ \\
\hline
\end{tabular}

Letras diversas na mesma coluna indicam diferenças estatísticas entre as médias.

Em análise dos valores medianos de células somáticas encontrados nesta pesquisa, segundo diferentes metodologias de contagens e colorações, observou-se que eles encontram-se abaixo do limiar de $0,75 \times 10^{6}$ células/mL de leite utilizado para avaliar a qualidade do leite de ovelhas pelo Ministério da Agricultura dos Estados Unidos (PAAPE et al., 2001).

$\mathrm{O}$ valor mediano de células somáticas do leite de ovelhas hígidas obtido nesta investigação foi inferior ao observado por BRITO et al. (2006), no leite de ovelhas Lacaune, utilizando o método automático de contagem celular. BARBOSA et al. (2006) também encontraram maior número de células somáticas no leite de ovelhas Santa Inês utilizando contador automático, diante dos observados nesta pesquisa. Segundo trabalhos disponíveis na literatura essas variações da CCS encontradas em trabalhos disponíveis na literatura são influenciadas por diversos fatores não infecciosos, como estresse, fase da lactação (BOSCOS et al., 1996; CONTRERAS et al., 1996; LAFI et al., 1998; SEVI et al., 2000; PAAPE et al., 2001; ALBENZIO et al., 2003; BERGONIER et al., 2003; LEITNER et al., 2003; BIANCHI et al., 2004; GONZALO et al., 2004; ANDERSON et al., 2005), número de lactações, frações do leite, raças, estados nutricionais (GONZÁLEZ-RODRÍGUEZ et al., 1995; FTHENAKIS, 1996; PAAPE et al., 2001; BERGONIER et al., 2003; ANDERSON et al., 2005) e por fatores patológicos como a infecção intramamária (CONTRERAS et al., 1996; KIRK et al., 1996; BURRIEL, 2000; PAAPE et al., 2001; BERGONIER et al., 2003).

A coloração de Rosenfeld não é específica para células nucleadas, pois não permite a diferenciação entre as células somáticas e os corpúsculos citoplasmáticos, presentes no leite de ovelhas Lacaune, o que pode ter aumentado aparentemente a contagem celular quando se utilizou este método de contagem. As amostras de leite coradas pela coloração de Rosenfeld apresentaram maior celularidade do que os valores encontrados nas contagens determinadas por contador automático e microscopia direta, utilizando-se o corante verde de metil e pironina-Y, que se baseia apenas na contagem de células nucleadas (ZENG \& ESCOBAR, 1996). Deve ser também considerado que, apesar de a CCS microscópica diferencial ser muito utilizada para caprinos e bovinos, ainda está sendo adaptada para o leite de ovelhas, que apresenta maior taxa de gordura do que o leite de vacas (PENGOV, 2001).

A coloração com verde de metil e pironina-Y é específica para células nucleadas, excluindo a presença dos corpúsculos citoplasmáticos presentes no leite de ovelhas, porém seu valor mediano foi inferior ao encontrado através da contagem automática em aparelho Fossomatic. Trata-se de resultados que podem ter ocorrido em virtude da calibração do aparelho automático com leite de vaca, o qual possui secreção láctea merócrina diferente da secreção apócrina de ovelhas (PAAPE et al., 2001). Além disso, alguns corpúsculos citoplasmáticos possuem porções nucleares, que podem ter sido contados durante o exame microscópico das lâminas coradas com verde de metil e pironina-Y.

No presente estudo, os valores de células mononucleares do leite de ovelhas Lacaune hígidas criadas no Rio Grande do Sul encontrados foram 0,094 e $0,141 \times 10^{6}$ células $/ \mathrm{mL}$ de leite, utilizando contagem microscópica direta, com corante de verde de metil e pironina-Y e Rosenfeld, respectivamente. Na CCS diferencial, os valores médios de leucócitos polimorfonucleares foram de 0,062 e $0,051 \times 10^{6}$ células/mL de leite, utilizando os dois corantes citados, respectivamente, observando-se predomínio de células mononucleares, nos dois métodos de coloração dos esfregaços lácteos.

Portanto, obteve-se predomínio de células mononucleares, mediante diferenciação do núcleo celular na contagem microscópica direta (Tabela 2), concordando com PAAPE et al. (2001) e discordando do experimento desenvolvido por CUCCURU et al. (1997), em que foi observado o aumento de células polimorfonucleares, relacionado com a redução da produção de leite. 
TABELA 2. Contagem de leucócitos mononucleares e polimorfonucleares do leite de ovelhas Lacaune hígidas criadas no Rio Grande do Sul, utilizando contagem microscópica direta com corante de verde de metil e pironina e Rosenfeld

\begin{tabular}{lcc}
\hline $\begin{array}{l}\text { Métodos de } \\
\text { coloração }\end{array}$ & Mononucleares & Polimorfonucleares \\
\hline Pironina & $94.488^{\mathrm{b}}$ & $62.992^{\mathrm{a}}$ \\
Rosenfeld & $141.480^{\mathrm{a}}$ & $51.090^{\mathrm{b}}$ \\
Significância & $\mathrm{P}<0,00001$ & $\mathrm{P}<0,00001$ \\
\hline
\end{tabular}

Letras diversas na mesma coluna indicam diferenças estatísticas entre as médias.

Porém, nas contagens em que se utilizou o corante de Rosenfeld, obtiveram-se um maior número de células mononucleares e menor número de células polimorfonuclares, em comparação com os resultados das contagens com verde de metil e pironina-Y. Este fato pode ter ocorrido em virtude da contagem dos corpúsculos citoplasmáticos com a coloração de Rosenfeld, identificados erroneamente como células mononucleares, pois o núcleo das células mononucleares impregna menos com o corante que o núcleo das células polimorfonucleares (BARBOSA et al., 2006). É importante lembrar que a celularidade e a distribuição de cada tipo celular são influenciadas por várias condições fisiológicas e patológicas da glândula mamária (MORGANTE et al., 1996).

\section{CONCLUSÕES}

Foi observado, no presente estudo, que, por meio da coloração de pironina-Y, há possibilidade de melhor identificação das células somáticas do leite e do tipo celular predominante.

\section{REFERÊNCIAS}

ALBENZIO, M.; TAIBI, L.; CAROPRESE, M.; DE ROSA, G.; MUSCIO, A.; SEVI, A. Immune response, udder health and productive traits of machine milked and suckling ewes. Small Ruminant Research, v. 48, p. 189-200, 2003.

ANDERSON, D. E.; HULL, B. L.; PUGH, D. G. Enfermidades da glândula mamária. In: PUGH, D. G. Clínica de ovinos e caprinos. São Paulo: Editora Roca, 2005. 513 p.

BARBOSA, D. A.; BLAGITZ, M. G.; AZEDO, M. R.; BATISTA, C. F.; GOMES, V.; BARBOSA, P. R.; BERGMANN, G. Com- posição do sangue e do leite em ovinos leiteiros do sul do Brasil: variações na gestação e na lactação. Ciência Rural, v. 36, 2006.

BENITES, N. R.; VERÍSSIMO, C. J.; DELLA LIBERA, A. M. M. P. Staining effect and evaluator influence on somatic cells count (SCC) of milk from sheep of Santa Inês breed yielded in São Paulo. Revista de Ciências Veterinárias, v. 4, p.16, 2006.

BERGONIER, D.; CRÉMOUX, R.; RUPP, R.; LAGRIFFOUL, G.; BERTHELOT, X. Mastitis of dairy small ruminants. Veterinary Research, v. 34, p. 689-716, 2003.

BIANCHI, L.; BOLLA, A.; BUDELLI, E.; CAROLI, A.; CASOLI, C.; PAUSELLI, M.; DURANTI, E. Effect of udder health status and lactation phase on the characteristics of Sardinian ewe milk. Journal of Dairy Science, v. 87, p. 2401-2408, 2004.

BOSCOS, C.; STEFANAKIS, A.; ALEXOPOUlOS, C.; SAMARTZI, F. Prevalence of subclinical mastitis and influence of breed, parity, stage of lactation and mammary bacteriological status on coulter counter and california mastitis test in the milk of Saanen and autichthonous Greek goats. Small Ruminant Research, v. 21, p. 139-147, 1996.

BRITO, M. A.; GONZÁLEZ, F. D.; RIBEIRO, L. A.; CAMPOS, R.; LACERDA, L.; BURRIEL, A. R. Somatic cell counts determined by coulter or fossomatic counter and their relationship to administration of oxytocin. Small Ruminant Research, v. 35, p. $81-84,2000$

CONTRERAS, A.; SIERRA, D.; CORRALES, J. C.; SANCHEZ, A.; MARCO, J. Physiological threshold of somatic cell count and california mastitis test for diagnosis of caprine subclinical mastitis. Small Ruminant Research, v. 21, p. 259-264, 1996.

CUCCURU, C.; MORONI, P.; ZECCONI, A.; CASU, S.; CARIA, A.; CONTINI, A. Milk differencial cell counts in relation to total counts in Sardinian ewes. Small Ruminant Research, v. 25, p. 169-173, 1997.

FTHENAKIS, G. C. Somatic cell counts in milk of WelshMountain, Dorset-Horn and Chios ewes throughout lactation. Small Ruminant Research, v. 20, p. 155-162, 1996.

GOMES, V.; DELLA LIBERA, A. M. M. P.; GARCIA, M.; BENITES, N. R.; MADUREIRA, K. M. Contagem de células somáticas no leite de caprinos. A Hora Veterinária, v. 22, n. 131, p. 45-47, 2002.

GOMES, V.; DELLA LIBERA, A. M. M. P.; MADUREIRA, K. M.; ARAÚJO, W. P. Effect of the stage of lactation on somatic cell counts in healthy goats (Caprae hircus) breed in Brazil. Small Ruminant Research, v. 64, p. 30-34, 2006. 
GONZÁLEZ-RODRÍGUEZ, M. C.; GONZALO, C.; SAN PRIMITIVO, F.; CÁRMENES, P. Relationship between somatic cell count and intramammary infection of the half udder in dairy ewe. Journal of Dairy Science, v. 78, p. 2753-2759, 1995.

GONZALO, C.; BOIXO, J. C.; CARRIEDO, J. A.; SAN PRIMITIVO, F. Evaluation of rapid somatic cell counters under different analytical conditions in ovine milk. Journal of Dairy Science, v. 87, p. 3623-3628, 2004.

GONZALO, C.; MARTÉNEZ, J.A.; CARRIEDO, J.A.; SAN PRIMITIVO, F. Fossomatic cell-counting on ewe milk: comparison with direct microscopy and study of variation factors. Journal Dairy Science, v. 86, p. 138-145, 2003.

INTERNATIONAL DAIRY FEDERATION. Laboratory methods for use in mastitis work. Brussels, 1981. 27 p. (Bulletin, 132).

KIRK, J. H.; GLENN, J. S.; MAAS, J. P. Mastitis in a flock of milking sheep. Small Ruminant Research, v. 22, p. 187-191, 1996.

KRIEG, N. R.; HOLT, J. C. Bergey's manual of sistematic bacteriology. 9. ed. Baltimore: Willians \& Wilkians, 1984. 787 p.

LAFI, S. Q.; AL-MAJALI, A. M.; ROUSAN, M. D.; ALAW$\mathrm{NEH}, \mathrm{J}$. M. Epidemiological studies of clinical and subclinical ovine mastitis in Awassi sheep in northern Jordan. Preventive Veterinary Medicine, v. 33, p. 171-181, 1998.

LEITNER, G.; CHAFFER, M.; CARASO, Y.; EZRA, E.; KABABEA, D.; WINKLER, M. GLICKMAN, A.; SARAN, A. Udder infection and milk somatic cell count, NAGase activity and milk compositions - fat, protein and lactose - in Israeli - Assaf and Awassi sheep. Small Ruminant Research, v. 49, p. 157-164, 2003.

MINITAB. The student edition of MINITAB Statistical software adapted for education. Release 13.0. User's Manual. New York: Addison-Wesley, 2000. CD-ROM.

MORGANTE, M.; RANUCCI, S.; PAUSELLI, M.; BEGHELLI, D.; MENCARONI, G. Total and differencial cell count by di- rect microscopic method on ewe milk. Journal of Veterinary Medicine, v. 43, p. 451-458, 1996.

PAAPE, M. J.; POUTREL, B.; CONTRERAS, A.; MARCO, J. C.; CAPUCO, A. V. Milk somatic cells and lactation in small ruminants. Journal of Dairy Science, v. 84, p. 237-244, 2001.

PENGOV, A. The role of coagulase-negative Staphylococcus spp and associated somatic cell counts in the ovine mammary gland. Journal of Dairy Science, v. 84, n. 3, p. 572-574, 2001.

PRESCOTT, S. C.; BREED, R. S. The determination of the number of the body cells in milk by a direct method. Journal of Infectious Diseases, v. 7, 632-640, 1910.

ROSENFELD, G. Corante pancrômico para hematologia e citologia clínica: nova combinação dos componentes de May-Grunwald e do Giemsa num só corante de emprego rápido. Memórias do Instituto Butantan, v. 20, p. 329-335, 1947.

SAMPAIO, I. B. M. Estatística aplicada à experimentação animal. 2. ed. Belo Horizonte: Fundação de Estudo e Pesquisa em Medicina Veterinária e Zootecnia, 2002. 265 p.

SEVI,A.;TAIBI,L.;ALBENZIO,M.;MUSCIO,A.;ANNIXXHIARICO, G. Effect of parity on milk yield, composition, somatic cell count, renneting parameters and bacteria counts of Comisana ewes. Small Ruminant Research, v. 37, p. 99-107, 2000.

ZENG, S. S.; ESCOBAR, E. N. Effect of breed and milking method on somatic cell count, standard plate count and composition of goat milk. Small Ruminant Research, v. 19, p. 169-175, 1996.

ZENG, S. S.; ESCOBAR, E. N. POPHAM, T. Daily variations in somatic cell count, composition, and production of Alpine goat milk. Small Ruminant Research, v. 26, p. 253-260, 1997.

ZENG, S. S.; ESCOBAR, E. N.; HART, S. P.; HINCKLEY, L.; BAULTHAUS, M.; ROBINSON, G. T.; JAHNKE, G. Comparative study of the effects of testing laboratory, counting method, storage and shipment on somatic cell counts in goat milk. Small Ruminant Research, v. 31, p. 103-107, 1999. 